The only other side effect encountered was nausea, which occurred in only one or two patients. No patient showed any evidence of cardiac decompensation as a result of oxprenolol administration. Oxprenolol, therefore, would appear to offer an advantage over propranolol in having less tendency to produce adverse effects on myocardial function. Whereas both propranolol and oxprenolol reduce the heart rate at rest and after exercise, oxprenolol leads to a smaller reduction of cardiac output than propranolol, since the resultant bradycardia with oxprenolol is compensated by a greater increase in stroke volume (Grandjean and Rivier, 1968). The other potential advantage is the less pronounced effect on bronchial muscle, though this aspect was not investigated in the present study. Beumer et al. (1968, 1969) have convincingly shown that oxprenolol produces much less bronchospasm in asthmatic patients than D-propranolol, and in fact it had as little effect on respiratory function as D-propranolol, in which the beta-blocking effect is much less pronounced than in its racemic isomer.

We are indebted to Dr. R. Rondel, of Ciba, for supplies of oxprenolol (Trasicor).

\section{References}

Bath, J. C. J. L. (1966). American fournal of Cardiology, 18, 415. Bender, F. (1968). Medizinische Welt, 2, 2481.
Beumer, H. M. (1968). Medizinische Klinik, 63, 1939.

Beumer, H. M. (1969). Pharmacologia Clinica, 1, 172.

Brunner, H., Hedwall, P. R., and Meier, M. (1968). Arzneimittel-Forschung, $18,164$.

Chamberlain, D. A. (1966). Cardiologia, 49, Suppl. No. 2, p. 27.

Dorph, S., and Binder, C. (1969). Acta Medica Scandinavica, 185, 443.

Epstein, S. E., and Braunwald, E. (1966). New England fournal of Medicine, $275,1106,1175$.

Frieden, J., Enselberg, C. D., Rosenblum, R., and Rosenberg, A. S. (1967). Circulation, 36, Suppl., p. 113

Grandjean, T., and Rivier, J. L. (1968). British Heart fournal, 30, 50.

Harrison, D. C. (1969). Cardiovascular Clinics, 1, 46.

Harrison, D. C., Griffin, J. R., and Fiene, J. T. (1965). New England fournal of Medicine, 273, 410 .

Irons, G. V., Ginn, W. N., and Orgain, E. S. (1967). American fournal of Medicine, 43, 161

Jewitt, D. E.; et al. (1969). Lancet, 1, 635.

own, B. (1968). In Acute Myocardial Infarction, ed. D. G. Julian and M. F. Oliver, p. 171. Edinburgh, Livingstone.

Lucchesi, B. R. (1965). Journal of Pharmacology and Experimental Therapeutics, 148, 94.

McNeill, R. S. (1964). Lancet, 2, 1101.

Nayler, W. G., Chipperfield, D., and Lowe, T. E. (1969). Cardiovascular Research, 3, 30.

Sandler, G., and Clayton, G. A. (1970). British Medical fournal, 2, 399.

Sekiya, A., and Williams, E. M. V. (1964). British fournal of Pharmacology, $21,473$.

Stephen, S. A. (1966). American fournal of Cardiology, 18, 463.

Stock, J. P. P. (1966). American fournal of Cardiology, 18, 444.

Stock, J. P. P., and Dale, N. (1963). British Medical fournal, 2, 1230.

Szekely, P., et al. (1966). American fournal of Cardiology, 18, 426.

Theilen, E. O., and Wilson, W. R. (1968). Medical Clinics of North America, 52, 1017.,

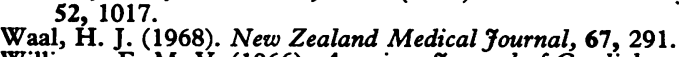

Williams, E. M. V. (1966). American fournal of Cardiology, 18, 399.

Wilson, D. F., Watson, O. F., Peel, J. S., Langley, R. B., and Turner, A. S. (1968). New Zealand Medical fournal, 68, 145.

\title{
Gonococcal Ophthalmia Neonatorum Despite Treatment with Antibacterial Eye-drops
}

\author{
C. B. S. SCHOFIELD, R. A. SHANKS
}

British Medical fournal, 1971, 1, 257-259

\section{Summary}

Over a five-year period, 1964-8, 48 cases of gonococcal ophthalmia neonatorum were notified to the department of venereology in Glasgow. Thirty-seven babies were born in hospital and 11 at home. The conjunctivitis, usually recorded as a "sticky eye," developed between 1 and 13 days of birth, 36 by the fourth day.

Diagnosis by culture of Neisseria gonorrhoeae was delayed in some cases up to $\mathbf{3 0}$ days after the appearance of the signs for those born in hospital and 15 days for those born at home, usually because of the blind use of antibacterial eyedrops which produced temporary alleviation of the signs without eradicating the infection; chloramphenicol was noteworthy in this respect.

A "sticky eye" will resolve without the use of antibacterial agents, ophthalmia neonatorum will not. When it is decided to use an antibacterial agent pretreatment conjunctival smears for immediate staining and swabs for culture should be taken and the case notified to the medical officer of health.

Gonococcal ophthalmia is a preventable disease. In view of the obstetricians' already heavily committed clinical work

Ruchill Hospital, Glasgow N.W.

C. B. S. SCHOFIELD, M.D., F.R.C.P.ED., Consultant Venereologist

Paediatric Department, Royal Maternity Hospital, Glasgow C.4

R. A. SHANKS, M.D., F.R.C.P.(LOND., GLASG.), Physician in charge load there is need for venereologists to collaborate, on consultation and within the maternity hospitals wherever possible, in the screening of antenatal patients for candidiasis and trichomoniasis as well as for gonorrhoea. Some target groups, those with a pathological vaginal discharge or with certain adverse social factors, warrant more thorough investigation, while all those treated require further examination to ensure cure.

\section{Introduction}

Despite the absence of accurate notification it is clear from published statistics that there has been a considerable increase in the incidence of gonorrhoea in most countries of the world (W.H.O., 1969). Certain aspects of this increase make it a matter of concern not only to venereologists but to obstetricians and paediatricians as well.

In England and Wales the incidence of gonorrhoea in 1958 was 22,398 males and 5,489 females, showing the usual male predominance. In 1968 the figures were 32,595 males and 12,367 females (Department of Health and Social Security, 1969). As elsewhere this considerable increase in the incidence of gonorrhoea in females has been seen in Glasgow-187 in 1958, 391 in 1968-the increase being mainly among teenagers and women in their early twenties (Department of Health and Social Security, 1969). It is not surprising, therefore, that gonococcal ophthalmia neonatorum should again make its appearance in a country where prophylactic instillation of eye-drops has been abandoned. In the report from England and Wales the figures for 1968 included 35 
cases of gonococcal ophthalmia neonatorum. In the same year there were 18 cases in Scotland, 12 of which were from Glasgow, a figure well above the national average.

A clinical and epidemiological study of ophthalmia neonatorum in Glasgow has been described elsewhere (Smith, 1969) and the medico-social background to gonococcal ophthalmia neonatorum has been dealt with by one of us (Schofield, 1969). The purpose of this paper is to review the management of babies before the diagnosis is made and to consider in detail what is to be done to eradicate this disease. Many of the infants affected were delivered in the Royal Maternity Hospital, Glasgow. The clinicians in the paediatric department of the hospital had already been concerned by the increasing numbers of clinical and bacteriological diagnoses. Prophylaxis had been abandoned for many years, and until recently this had seemed to be a justified policy. The question has now arisen whether prophylaxis should be reintroduced in the light of recent circumstances, whether as an isolated measure it is effective enough, and whether it is a legitimate practice from the public health point of view.

During the five-year period 1964-8 48 cases of gonococcal ophthalmia neonatorum were referred to the department of venereology in Glasgow; 24 were male and 24 female. A retrospective study has been made, using information obtained from maternity units, eye departments, infectious diseases hospitals, and general practitioners as well as from the venereal diseases clinics, concerning the antenatal management of the mothers and the postnatal care of the babies.

\section{Results}

Thirty-seven of the babies were born in hospital (16 of them in the Royal Maternity Hospital, Glasgow) and 11 at home. None had eye-drops instilled prophylactically. The yearly distribution according to place of birth is given in Table $I$. According to the case records the conjunctivitis, usually recorded as a "sticky eye," developed between 1 and 13 days of birth, 36 within five days. The day of onset and the place of birth are given in Table II. An accurate bacteriological diagnosis, however, was not obtained until anything between 1 and 30 days after the clinical diagnosis for those born in hospital and 1 to 15 days for those born at home.

TABLE I-Year and Place of Birth

\begin{tabular}{lcc|c|c|c|c|c|c}
\hline \multicolumn{2}{r|}{ Place of Birth } & 1964 & 1965 & 1966 & 1967 & 1968 & Total \\
\hline Home & $\ldots$ & $\ldots$ & 1 & 4 & 4 & 2 & 0 & 11 \\
Hospitai & $\ldots$ & $\ldots$ & 1 & 5 & 11 & 10 & 10 & 37 \\
\hline & Total & $\ldots$ & 2 & 9 & 15 & 12 & 10 & 48 \\
\hline
\end{tabular}

TABLE II-Reported Onset of Sticky Eye by Place of Birth

\begin{tabular}{|c|c|c|c|c|c|c|c|c|c|c|c|}
\hline \multirow{2}{*}{$\begin{array}{c}\text { Place } \\
\text { of } \\
\text { Birth }\end{array}$} & \multicolumn{10}{|c|}{ Day of Onset } & \multirow{2}{*}{ Total } \\
\hline & 1 & 2 & 3 & 4 & 5 & 6 & 7 & 9 & 10 & 13 & \\
\hline $\begin{array}{l}\text { Home } \\
\text { Hospital } \ldots\end{array}$ & $\begin{array}{l}3 \\
6\end{array}$ & $\begin{array}{c}3 \\
10\end{array}$ & $\begin{array}{l}1 \\
8\end{array}$ & $\begin{array}{l}1 \\
4\end{array}$ & $\frac{1}{2}$ & 1 & $\overline{3}$ & $\overline{1}$ & $\overline{1}$ & 1 & $\begin{array}{l}11 \\
37\end{array}$ \\
\hline Total & 9 & 13 & 9 & 5 & 3 & 2 & 3 & 1 & 1 & 2 & 48 \\
\hline
\end{tabular}

There can be no doubt that the delay in diagnosis was often associated with the blind treatment of the "sticky eyes" by the instillation of antibacterial eye-drops. The delay associated with the various eye-drops is set out in Table III. Of the babies born in hospital $23(62 \%)$ were so treated and of those born at home $9(82 \%)$. No baby received any form of systemic antibiotic therapy, but the local treatment did suppress the gonococcal infection without curing it. All 48 babies were finally treated and cured with penicillin, usually given systemically, as well as locally-45 in infectious diseases hospitals and three at home.

In every case the ultimate diagnosis of gonorrhoea was made by culture in a bacteriological laboratory-19 in maternity hospitals, 6 in infectious diseases hospitals, 14 in eye departments, and 9 by public health laboratories.

\section{Discussion}

It is clear that the delay in reaching the correct diagnosis in this series was in most cases due to inadequate treatment without previous bacteriological investigation. The treatment was inadequate because either the wrong antibacterial agent was selected for topical application or it was inadequately applied, or perhaps both. Chloramphenicol was the drug most frequently used, and in this particular case it has the disadvantage of causing clinical improvement without eradicating the causative organism, with consequent relapse when the treatment is stopped. All the cases of gonococcal ophthalmia neonatorum were cured eventually by systemic penicillin and/or the instillation of penicillin eye-drops, though not always as frequently as recommended by Sorsby (1950).

Ophthalmia neonatorum, irrespective of cause, has been a notifiable disease in Britain since 1914. It was defined in a Statutory Rule and Order (Ministry of Health, 1926) as a "purulent discharge from the eyes of an infant commencing within twenty-one days of its birth." The need for routine notification and its beneficial effects in the prevention of blindness, even before the discovery of the antibiotics, is well brought out by Assinder (1943) in his study of ophthalmia neonatorum in Birmingham from 1928 to 1942; as notifications rose the incidence of blindness fell. Notification remains as important as it ever was, especially if it coincides with proper bacteriological investigation before treatment.

Currently, there appears to be gross underreportmg of ophthalmia neonatorum, and this is probably due in part to its not being distinguished from the ubiquitous "sticky eye" in maternity hospitals. Differentiation would be helped if it could be agreed that a "sticky eye" will clear with local hygiene and without local antibacterial therapy, but ophthalmia neonatorum would depend on the clinician's decision to treat the infant with an antibacterial agent. Before starting treatment with an antibacterial agent smears and cultures should be taken to obtain a bacterial diagnosis. If the cultures showed organisms resistant to the initial treatment this could be changed to an appropriate one before irreparable damage was done to the conjunctiva. Moreover, the high concentration of penicillin obtained by local instillation will inhibit even organisms normally resistant to penicillin.

TABLE III-Delay in Diagnosis (Days) by Treatment Given (Numbers Born at Home Shown in Parentheses)

\begin{tabular}{|c|c|c|c|c|c|c|c|c|c|c|c|c|c|c|c|c|c|c|c|c|}
\hline \multirow{2}{*}{\multicolumn{3}{|c|}{ Type of Eye-drops }} & \multirow{3}{*}{$\begin{array}{c}\begin{array}{c}\text { Number } \\
\text { Treated }\end{array} \\
9 \\
9 \\
5 \\
5 \\
2 \\
2 \\
16\end{array}$} & \multicolumn{17}{|c|}{ Number of Days Delay } \\
\hline & & & & \multirow[b]{2}{*}{$\begin{array}{l}0 \\
2\end{array}$} & \multirow[b]{2}{*}{$\begin{array}{l}1 \\
1 \\
1 \\
7(1)\end{array}$} & \multirow[b]{2}{*}{$\begin{array}{l}2 \\
2(1)\end{array}$} & \multirow[b]{2}{*}{$\begin{array}{l}3 \\
1 \\
1 \\
1 \\
2 \\
2\end{array}$} & \multirow{2}{*}{$\begin{array}{l}4 \\
1 \\
2\end{array}$} & \multirow[b]{2}{*}{$\begin{array}{l}5 \\
1 \\
2 \\
1 \\
1\end{array}$} & \multirow{2}{*}{$\begin{array}{l}6 \\
2 \\
(1) \\
(1)\end{array}$} & \multirow{2}{*}{\begin{tabular}{|c|}
7 \\
1 \\
1 \\
1 \\
$(1)$
\end{tabular}} & \multirow{2}{*}{$\frac{8}{1}$} & \multirow{2}{*}{$\begin{array}{l}9 \\
(1)\end{array}$} & \multirow{2}{*}{$\frac{10}{(2)}$} & \multirow{2}{*}{$\frac{15}{2(1)}$} & \multirow{2}{*}{$\frac{18}{1}$} & \multirow{2}{*}{$\frac{20}{1}$} & \multirow{2}{*}{21} & \multirow{2}{*}{$\frac{29}{1}$} & \multirow{2}{*}{$-\frac{30}{1}$} \\
\hline 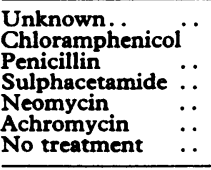 & $\begin{array}{l}\ldots \\
\cdots \\
\cdots \\
\cdots \\
\cdots\end{array}$ & $\begin{array}{l}\ldots \\
\because \\
\because \\
\because \\
\cdots \\
\end{array}$ & & & & & & & & & & & & & & & & & & \\
\hline & Total & $\ldots$ & 48 & 2 & $9(1)$ & $3(1)$ & 7 & 3 & 5 & $4(2)$ & $4(1)$ & 1 & (1) & (2) & $2(1)$ & 1 & 1 & (1) & 1 & 1 \\
\hline
\end{tabular}


Gonorrhoea is the cause of only a small proportion of cases of ophthalmia neonatorum, most being due to other organisms, such as staphylococci, Escherichia coli, and other coliforms. In addition, the TRIC agent (Chlamydia oculogenitalis) may cause an ophthalmia which develops usually after the tenth day of life, sometimes after the successful treatment of a gonococcal or other bacterial ophthalmia. The clinician therefore requires the support of an adequate bacteriological service that can make an accurate diagnosis and provide the results of sensitivity tests within four days. Ophthalmia neonatorum should be treated only in centres having such laboratory facilities.

Whenever gonorrhoea is diagnosed in a baby the mother requires an immediate examination, including smears and cultures taken from urethra, cervix, and possibly the rectum, so that she can receive the correct treatment for her gonorrhoea. This is of the utmost importance as there is a special risk of salningitis developing during the puerperium.

The risk of blindness due to untreated ophthalmia neonatorum would nowadays appear to be negligible in the developed countries, where effective antibiotics are freely available. In Britain there have been no such renorts since routine prophylaxis was discontinued. In developing countries, however, where facilities for adequate treatment may not yet be available, prophylaxis may still have a place in preventing a proportion of cases of ophthalmia neonatorum. Chemical conjunctivitis due to the instillation of $1 \%$ silver nitrate solution does occur, causing "sticky eyes," but the incidence following colloidal silver preparations is probably minimal. In the U.S.A., where prophvlaxis is required legally, the late effects of gonococcal ophthalmia neonatorum fell from $24.1 \%$ in 1914 to $0.3 \%$ in $1958-9$ (Barsam, 1966). Nevertheless, recent reports of failure of silver nitrate preparations have been published from the U.S.A. (Friendly, 1969) and from Finland (Osterlund et al., 1968).

A large study, testing various methods of prophylaxis, has been reported from New York City (Greenberg and Vandow, 1961). Among some 472,000 infants the rate per 100.000 of gonococcal ophthalmia after no prophylaxis was 121.4 , after saline irrigation 130.4 , after $1 \%$ silver nitrate $15 \cdot 5$, after topical antibiotics 20.8, and after an intramuscular injection of penicillin zero. Intramuscular penicillin, the only measure $100 \%$ effective, would appear to be contraindicated as potentially causing sensitization and possible anaphylaxis at a later date when it could have been life-saving. Apart from the potential danger of the prophylactic agents to the infants, whenever they are effective the gonococcal infections in the mothers will be missed until they become symptomatic, possibly with salpingitis, or are later notified as contacts when they have infected others. This might well be considered a greater public health hazard than awaiting the development of ophthalmia neonatorum in the infants.

Gonococcal ophthalmia neonatorum is a preventable disease, as is congenital syphilis, which has almost been eradicated wherever routine prenatal serological screening is carried out. Unfortunately, as yet there is no reliable serological test for gonorrhoea, which is largely asymptomatic in women. The almost complete uselessness of even "high" vaginal smears for this purpose cannot be overemphasized. The technique for the diagnosis in women is crucial (Catterall, 1970). including as it does the taking of smears for staining and cultures from the cervix as well as from the urethra; $30 \%$ of cases are apt to be missed if only one investigation is performed. Successful routine screening of this kind has been reported from the U.S.A. (Cave et al., 1969) and Canada (Waters and Roulston, 1969), but many of the large maternity units in this country would find such a task bevond their clinical manpower.

Ideally every pregnant woman should be screened for vaginal candidiasis and Trichomonas vaginalis infestation, avart from the less common neisserian infection, and all those found to have any of these conditions should be re-examined after treatment to ensure cure. All cases of vaginal discharge, especially if it is offensive, irritating, or associated with dvsuria, warrant thorough investigation, which entails more than a single screening test, as do those women with adverse social histories (Schofield, 1969). It is here that there is a great need for collaboration between the obstetrician and the venereologist, the latter undertaking the examination, on referral and within the maternity hospital wherever possible. of all these women, especially those at greatest risk, as well as taking posttreatment tests of cure and tracing the contacts of any sexually transmitted disease.

We wish to thank all those who took so much trouble to provide us with information not available in our own records, doctors in general practice and in the hospital service. and especially the hospital records officers, without whose help this investigation would not have been possible.

\section{References}

Assinder, E. (1943). British Fournal of Venereal Diseases, 19, 173. Barsam, P. C. (1966). New England fournal of Medicine, 274, 731. Catterall, R. D. (1970). British Fournal of Hospital Medicine, 3, 55. Cave, V. G., Bloomfield, R. D., Hindle, E. S., Gordon, W. E., and Hammock, D. (1969). Fournal of the American Medical Association, 210, 309.

Department of Health and Social Security (1968). Annual Report of the Chief Medical Officer. London, H.M.S.O., 1969.

Friendly, D. S. (1969). Clinical Proceedings of the Children's Hospital, 25, 1. Friendly, D. S. (1969). Clinical Proceedings of the Children's Hospital, 25, 1.
Glasgow Corporation (1968). Report of the Medical Officer of Health. Glasgow, The Corporation, 1969.

Greenberg, M., and Vandow, J. E. (1961). American fournal of Public Health and the Nation's Health 51, 836.

Ministry of Health (1926). Statutory Rules and Orders, No. 971.

Osterlund, K., Purola, E., and Jakkola, M. (1968). Ann. Paed. Fenn., 14, 23. Schofield, C. B. S. (1969). Lancet, 2, 1182 .

Smith, J. A. (1969). Scottish Medical fournal, 14, 272.

Sorsby, A. (1950). British fournal of Venereal Diseases, 26, 57.

Waters, J. R., and Roulston, T. M. (1969). American Fournal of Obstetrics and Gynecology, 103, 532.

World Health Organization (1969). Statistics Report, 22, No. 5. 